\title{
Classical conditioning of excitement anticipatory to food reward: Partial reinforcement
}

EDWARD ZAMBLE ${ }^{2}$

YALE UNIVERSITY

Rats were trained with a tone followed by food delivered independently of their behavior on $50 \%$ of the trials. Although activity increased during the CS there was no evidence for inhibition of delay as with 100\% reward, supporting a conditioned excitement theory of instrumental learning.

In a two-process incentive theory of reinforcement (e.g., Sheffield, 1965) it is assumed that classically conditioned excitement controls the pattern of emission of any instrumentally rewarded response. A previous paper (Zainble, 1967) showed that Pavlovian inhibition of delay develops with extended training in the increased activity anticipatory to food reward (Sheffield \& Campbell, 1954). Since the activity response is seen as a measure of conditioned excitement, the appearance of inhibition of delay was used to explain the commonly observed changes with practice in the pattern of speed or vigor of an instrumental response.

Several studies have shown that the vigor of responding near the beginning of an instrumental response chain may be greater under partial reinforcement (PR) than with $100 \%$ reward (e.g., Goodrich, 1959). If it could be shown that inhibition of delay for the conditioned excitement (activity) response does not develop under PR, this effect as well may be explained in the framework of conditioned excitement theory, as follows. Without inhibition of delay, most of the activity under PR would appear at the beginning of the response chain, even after prolonged training. In such a case the temporal gradients of conditioned excitement for PR and $100 \%$ might be expected to cross, with the amount of excitement produced by PR greater than $100 \%$ at the beginning of the CS but less toward the end. An instrumental response under the control of conditioned excltement would reflect these differences in relative vigor or speed of responding.

\section{Subjects and Apparatus}

The Ss were eight Holtzman Sprague-Dawley male rats about 100 days old at the start of the experiment.

The activity measuring system has been described before (Zamble, 1967). The $S$ was placed in a round cage 9 in. in diameter, with a foodcup mounted instde. Movements of the cage displaced a speaker coil, and the resultant voltage was used to trigger a digital pulse which was recorded on a printout counter. The experimental cage was mounted in a semi-soundproof chamber with lllumination from a $15 \mathrm{~W}$ bulb. The rewards consisted of $45 \mathrm{mg}$ Noyes pellets delivered by means of a plastic tube from a feeder mounted above the chamber. The CS was a $1000 \mathrm{cps}$ tone $5 \mathrm{~dB}$ above background.

\section{Precedure}

Ss were put on a dally feeding schedule of $11 \mathrm{~g}$ ground Purina chow mixed with water. After 16 days, habituation was begun. Ss were placed in the activity apparatus for $2 \mathrm{~h}$ on each of two consecutive days. On the next day Ss were trained to approach the foodcup on food delivery, with pellets given at random intervals.

On the first training day Ss were placed in the apparatus $2 \mathrm{~h}$ and $45 \mathrm{~min}$ before their feeding time. After a $15 \mathrm{~min}$ habituation period, training was begun. There were 20 dally trials, 4-6 min apart. On each trial the tone was presented for $11 \mathrm{sec}$; after the 10th second a single pellet was delivered. Activity was recorded continuously for $60 \mathrm{sec}$ starting $10 \mathrm{sec}$ before CS onset. After the last trial Ss were removed to their home cages where they were fed the remainder of their daily ration $30 \mathrm{~min}$ later.

There were 3 days of $100 \%$ reward, after which a $50 \%$ schedule was instituted for Days 4 through 15; on nonreinforced trials the CS went off after $11 \mathrm{sec}$. Reward was determined by a random series, bound by a limit of three consecutive trials of either type and a requirement of 10 rewarded trials in each session. After the 12 days training on PR, reward was discontinued entirely for two days of extinction (Days 16 and 17).

nesults

Activity during the CS quickly rose on the first training day. As can be seen in Fig. 1, most of the response occurred at the beginning of the CS. Activity during the CS was stgnificantly greater than during the $10 \mathrm{sec}$ pre-CS period on Day $1(t=3.06$, df $=7, p<.01$, onetailed).

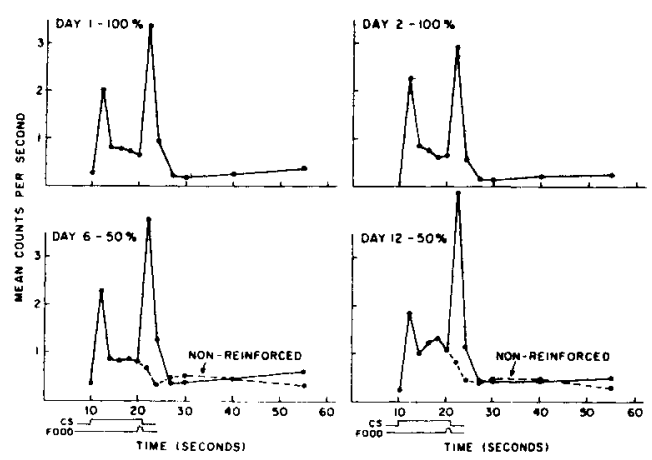

Fig. 1. Average activity rate showing response to CS and food on selected training days. Non-reinforced trials are separated from reinforced trials starting with usual time of food delivery. 


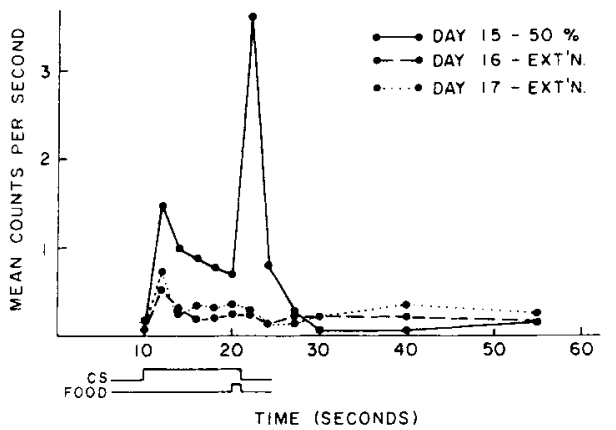

Fig. 2. Average activity rate during last acquisition day and extinction sessions.

There were no significant changes in the size of the response after Day 1, as measured by activity either during the entire CS or during $2 \mathrm{sec}$ segments. Fig. 1 shows also that the form of the response remained virtually unchanged after the introduction of PR. There was little evidence for the development of inhibition of delay even on Day 15 (Fig. 2).

During extinction the response dropped off quite rapidly. A t test of the increases above the baseline rate of Days 15 and 16 shows the decline to be significant $(t=4.05, d f=7, p<.01)$. The second extinction day showed no further decline (Fig. 2) indicating that the conditioned response was effectively extinguished during Day 16.

\section{Discussion}

The lack of inhibition of delay under PR supports the interpretation stated above. The present data are another example of a parallel between the patterns of activity during a CS for noncontingent food delivery and that of an instrumental response under an analogous reward schedule.

These results do not unequivocally support the condi- tioned excitement position, however. As an alternative it could be claimed that some (unspecified) behavior was learned by adventitious instrumental contingencies in the Pavlovian reward situation. The pattern of recorded activity would then show only that behavior and be entirely irrelevant to any conditioning process.

However, the extremely rapid extinction of the increased CS activity under PR argues against any major influence from instrumental factors. Although no direct statistical comparison can be made, resistance to extinction after training under almost identical conditions with $100 \%$ reward (Zamble, 1967) was somewhat greater. Slivka \& Bitterman (1966) used a similar measure with pigeons and found the same lack of greater resistance to extinction under PR. Since increased resistance to extinction after training with PR seems not to occur in classical conditioning as it does in instrumental situations, the evidence thus favors viewing the present effect as the result of a Pavlovian process.

\section{References}

GOODRICH, K. P. Performance in different segments of an instrumental response chain as a function of reinforcement schedule. $J$. exp. Psychol, 1959, 57, 57-63.

SLIVKA, R. M., \& BITTERMAN, M. E. Classical appetitive conditioning in the pigeon. Partial reinforcement. Psychon. Sci, 1966, 4, 181-2.

SHEFFIELD, F. D. Relation between classical conditioning and instrumental learning. In W. Prokasy (Ed.) Classical Conditioning. New York: Appleton-Century-Crofts, 1965.. Pp. 302-322.

SHEFFIELD, F. D., \& CAMPBELL, B. A. The role of experience in the "spontaneous" activity of hungry rats. J. comp. physiol. Psychol., 1954, 47, 97-100.

ZAMBLE, E. Classical conditioning of excitement anticipatory to food reward. J. comp. physiol. Psychol., 1967, 63, 526-529.

Notes

1. This research was supported by National Science Foundation Grant GB-04404. The author was a NSF Predoctoral Fellow.

2. Now at Institute for Cognitive Studies, Rutgers University, Newark, N. J.

\section{Erratum}

Davis, S. F., \& North, A. J. The effect of varied reinforcement training on behavior following incentive reduction. Psychon. Sci., 1967, 9 (7A), 395-396.-On page 395, right-hand column, fifth line from the bottom, beginning with "At terminal acquisition" and ending with "respectively," the text should be changed to read: "At terminal acquisition, Group VR differed significantly from Group $C(t=1.929$, df $=31, p<.05)$. From incentive reduction Trial Block 2 through Trial Block 6 Group VR differed significantly from Group LR $(t=2.259,2.289,2.889,2.346,2.22 ; \mathrm{df}=31, \mathrm{p}<$ $.05, .05, .01, .05, .05$, respectively)." 